\title{
ANALYSIS OF OPINIONS FOR GREEN BENEFITS: INSIGHTS FOR MARKETING OF ELECTIRC TWO WHEELERS
}

\author{
Dr. Mrudula Trivedi \\ Assistant Professor, Dept. of Commerce and Business Management \\ Faculty of Commerce, The Maharaja Sayajirao University of Baroda, India
}

\begin{abstract}
Two wheeler Industry has showing continuous and steady growth over the year in India and supported by its population based and consumption based growth. So, it offers sound growth opportunities for businesses based on innovations. But during this journey of growth it has lost balance in terms of protecting the environment. If we take case of petrol driven two wheelers, then indeed it has delivered the desired personal mobility option successfully but it has discharged pollution as well. So, the result is we are enjoying personal mobility convenience and paying huge invisible cost to health and damaging the mother earth. Environment protection is a serious concern globally and a challenge for two-wheeler marketers about how to minimise adverse effects of two wheelers. There is a huge scope for launching eco friendly two wheelers which can satisfy transportation need and minimizes pollution too. In this study an effort is made to understand consumers' willingness to make sacrifices for green benefits. Indian consumers are price conscious and therefore only launching innovation is not enough. If growth is required then innovation has to be priced wisely which can penetrate in the market and along with profit, company can also protect the environment. Study focuses on male and female users and their opinion about various dimensions related to their willingness to make compromises for green benefits.
\end{abstract}

Key words: Two-wheeler Industry, pollution, electric two wheeler, compromises for green benefits, exploring market segments.

Cite this Article: Dr. Mrudula Trivedi, Analysis of Opinions for Green Benefits: Insights for Marketing of Electirc Two Wheelers, International Journal of Production Technology and Management (IJPTM), 10(1), 2019, pp. 43-48.

http://iaeme.com/Home/issue/IJPTM?Volume=10\&Issue $=1$

\section{INTRODUCTION}

Two-wheeler Industry has witnessed tremendous growth over the year in India but lost balance in the process in terms of protecting the environment. If we take case of petrol driven two wheelers, then indeed it has delivered the desired personal mobility option successfully. But in the process it has discharged pollution as well. So, the result is we are enjoying personal 
mobility convenience and paying huge invisible cost to health and damaging the mother earth. Environment protection is a serious concern globally and a challenge for two-wheeler marketers about how to minimise adverse effects of two wheelers.

According to ICRA Two-wheeler sales likely to grow at 8-10\% in financial year 2019 and industry outlook is stable. (Two wheeler sales likely to grow) This sector is growing continuously and offers huge opportunities for innovations led business practices and move towards green two wheelers.

Market watchers believe that two-wheelers will help grow the EV segment-after all, sales of two-wheelers in India outpace those of cars 5:1 (cars sell about three million a year). "We will see electric two-wheelers as a way to adapt proclivity of electric mobility in India, instead of forced adoption through four-wheelers," says Rebecca Lindland, senior director and executive analyst at California-based vehicle valuation and auto research firm, Kelley Blue Book. (An electric vehicle and two wheels of change)

"It will take some time but two-wheelers will take off much faster than cars," says Abdul Majeed, partner at consulting firm PwC India. "In the next two to three years, a lot of electric scooters will be sold." (An electric vehicle and two wheels of change)

\section{POLLUTION A SERIOUS PROBLEM}

Several studies indicate that two-wheelers alone contribute more than $50 \%$ of the pollution. This Pollution has directly attacked on sustainability of the business itself along with mother nature.

Further, since two-wheeler industry is characterized as an oligopoly market, non-price competition is used as a weapon in the industry. Therefore, the most effective strategy in oligopoly is product differentiation. Eco-friendly two-wheelers and green competitive advantage can be taken to build unique image in the market profitably.

Electric/battery-operated two wheelers against the petrol driven two- wheeler definitely reduces pollution. At the same time, it reduces oil consumption and thereby less dependency on oil exporting countries. At present, Battery-operated two-wheelers are available in India which is environmental friendly. However, battery-operated two wheelers are just in the introductory stage of product life cycle in India. It is facing teething troubles at present, in terms of relatively weak performance against petrol driven vehicles.

Market watchers believe that two-wheelers will help grow the EV segment — after all, sales of two-wheelers in India outpace those of cars 5:1 (cars sell about three million a year). "We will see electric two-wheelers as a way to adapt proclivity of electric mobility in India, instead of forced adoption through four-wheelers," says Rebecca Lindland, senior director and executive analyst at California-based vehicle valuation and auto research firm, Kelley Blue Book. (An electric vehicle and two wheels of change)

Others agree. "It will take some time but two-wheelers will take off much faster than cars," says Abdul Majeed, partner at consulting firm PwC India. "In the next two to three years, a lot of electric scooters will be sold."

\section{RESEARCH OBJECTIVES}

1. To analyse consumers' concern for environment and willingness to pay more for eco-friendly two-wheeler.

2. To get insight in consumer behaviour for effective green marketing of two-wheelers. 


\section{RESEARCH METHODOLOGY}

This study was undertaken in Gujarat state with 1000 respondents consisting of male and female users of two wheelers were approached to elicit desired response.

Likert scale was used ranging from strongly agree to strongly disagree which will help in eliciting their agreement or disagreement and the extent of agreement or disagreement about a particular statement. To conduct the analysis, each statement was assigned a numerical score ranging 1 to 5 . Here, value 1 was assigned for strongly agree and value 5 was assigned for strongly disagree. To know opinion differences for both the gender two tailed t-test was used.

\section{ANALYSIS AND FINDINGS}

Respondents were asked to rate their opinions on five statements about battery operated twowheeler and Likert scale was used ranging from strongly agree to strongly disagree to measure the response.

- I will prefer to buy this two-wheeler as it is environmental friendly.

- I will buy it even if it is somewhat expensive.

- I will compromise with speed of this two wheeler as it protects the environment.

- I will compromise with speed as its operating cost is very low.

- Govt. should introduce special subsidy for such two wheelers.

Two-tailed t-test was performed to analyze the data.

$\mathrm{H}_{0}$ : Mean opinion rating of both the genders is equal for all five statements.

$\mathrm{H}_{1}$ : Mean opinion rating of both the genders is not equal for all five statements. 
Table 1 Independent Samples Test

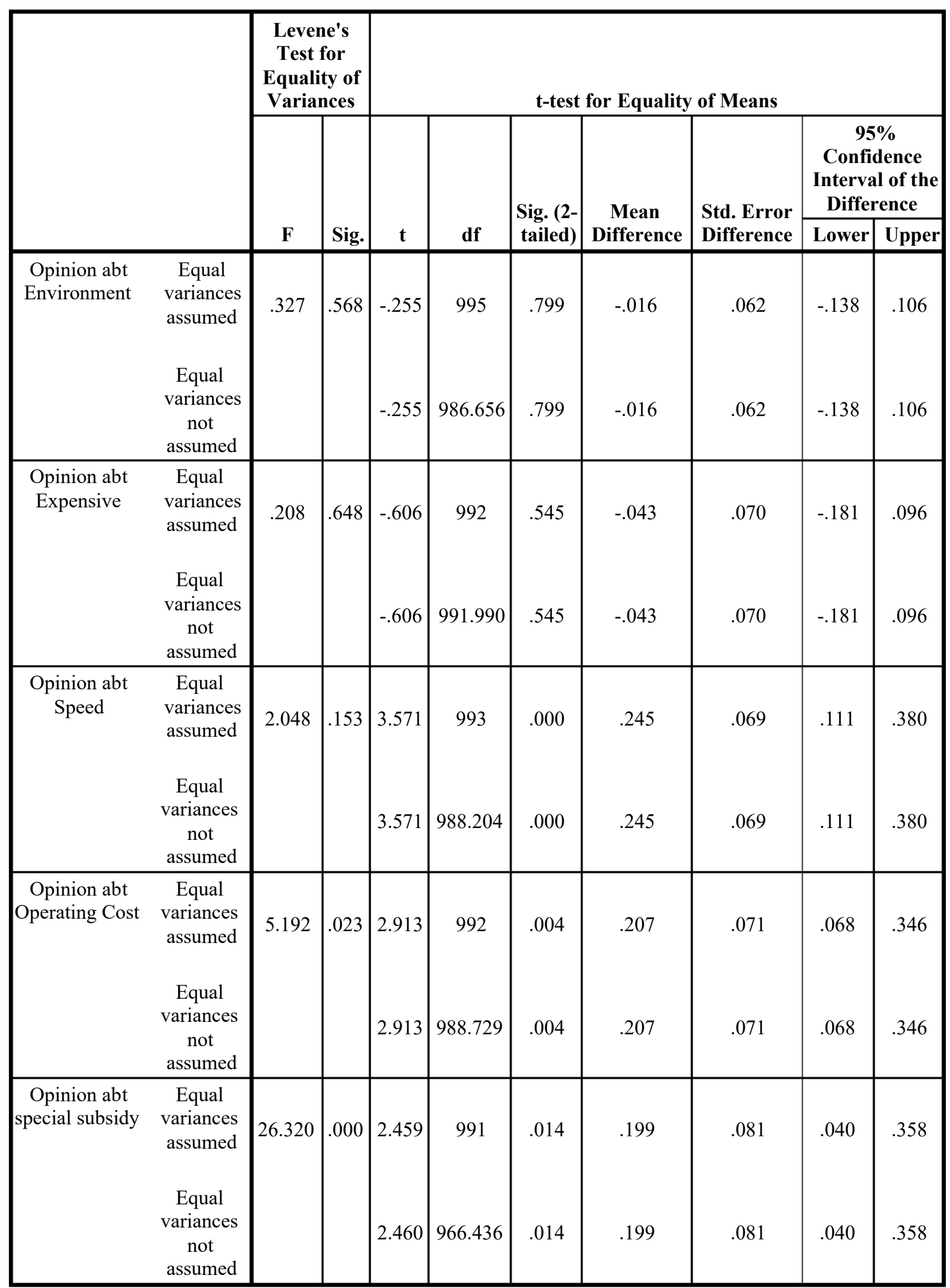


Here for statement $1 \& 2 p$-value was $.799 \& .545$ respectively which is $>.05$. Hence, $\mathrm{H}_{0}$ cannot be rejected for statement $1 \& 2$. So we infer that average opinion rating of both the gender is identical for statements $1 \& 2$. Mean values were identified with reference to opinion rating of both the genders.

Table-2 Group Statistics

\begin{tabular}{|cc|c|c|c|c|}
\hline & Gender & N & Mean & Std. Deviation & $\begin{array}{c}\text { Std. Error } \\
\text { Mean }\end{array}$ \\
\hline Opinion abt Environment & Male & 499 & 1.90 & .938 & .042 \\
& Female & 498 & 1.91 & 1.026 & .046 \\
\hline Opinion abt Expensive & Male & 499 & 2.28 & 1.117 & .050 \\
& Female & 495 & 2.33 & 1.105 & .050 \\
\hline Opinion abt Speed & Male & 499 & 3.08 & 1.124 & .050 \\
& Female & 496 & 2.84 & 1.042 & .047 \\
\hline Opinion abt Operating Cost & Male & 498 & 3.18 & 1.154 & .052 \\
& Female & 496 & 2.97 & 1.085 & .049 \\
\hline Opinion abt special subsidy & Male & 498 & 2.14 & 1.377 & .062 \\
& Female & 495 & 1.94 & 1.166 & .052 \\
\hline
\end{tabular}

For statement 1 mean value of male was 1.90 and in case of females it was 1.91. It means both the genders agree with the statement i.e. they will prefer to buy battery-operated twowheeler as it is eco-friendly. For statement 2 mean value of males was 2.28 and of females it was 2.33. Although these mean values are close to 2 , it does not give any strong indication of agreement for statement 2 .

Hence, we infer that both the gender do not show strong agreement or disagreement for willingness to buy battery-operated two-wheeler even if it is somewhat expensive.

For statements $3,4 \& 5 p$-value was found $.000, .004$ and .014 which is $<.05$. Hence, $\mathrm{H}_{0}$ is rejected in favour of $\mathrm{H}_{1}$ for all the three statements. So we conclude that average opinion rating of both the gender, differ for statement $3,4 \& 5$. If we refer mean values from the above table, we can infer that more number of females were willing to compromise with speed as it protects the environment against their male counterparts.

Similarly, more number of females here willing to compromise with speed as its operating cost is very low, against their male counterparts.

At last more number of females were of the opinion that govt. should introduce special subsidy for battery-operated two-wheeler as compared to male respondents.

\section{CONCLUSIONS}

Respondents were asked their opinions about their willingness to make compromises for buying a battery-operated two wheeler. Whether opinions differ gender wise was analyzed with reference to various statements under study.

It is concluded that both the gender agree with the statement i.e. they will prefer to buy battery-operated two-wheeler as it is eco-friendly. But at the same time, both the gender do not show strong agreement or disagreement for willingness to buy battery-operated two-wheeler even if it is somewhat expensive. Hence, there is no strong desire to pay somewhat more for 
green benefits. This shows that our consumers are indeed price conscious and therefore, offering battery-operated two-wheeler at the right price is indeed a challenge and most critical task for a marketer. Since, this two-wheeler has a potential to appeal to the masses, it must be reasonably priced to penetrate in the market because majority of the respondents like to buy this two-wheeler as it is environmental friendly but not willing to pay somewhat more for green benefits.

It is important to understand that more number of females were willing to compromise with speed as it protects the environment against their male counterparts. Similarly, more number of females here willing to compromise with speed as its operating cost is very low, against their male counterparts.

Hence, one of the important segment that marketer should target is female users rather than male users so that market entry would be smooth and market penetration of this vehicle becomes faster.

Keeping in mind male users more research and new technological break through is required for higher performance of this two wheeler to improve its speed, to keep its operating cost as low as possible. Government should play proactive role to make people sensitive about environment and to make compromises for green benefits.

\section{LIMITATIONS}

This study was mainly focused only on male and female users. Stratification of the target population and analysis of each strata would give more insight and accurate results. So, this study can be done.

\section{REFERENCES}

[1] An electric vehicle and two wheels of change:

[2] Available at https://www.livemint.com/, accessed on $21^{\text {st }}$ April, 2019.

[3] Two wheeler sales likely to grow: Available at: https://auto.economictimes.indiatimes.com/news/two-wheelers/motorcycles/twowheeler-sales-likely-to-grow-at- 8-10-in-fy19-industry-outlook-stable-icra/67255892, accessed on 21st March, 2019. 